\title{
Epidemiology, prognostic factors, and outcome of trauma patients admitted in a Brazilian intensive care unit
}

This article was published in the following Dove Press journal: Open Access Emergency Medicine

\author{
Gabriella F Pogorzelski' \\ Taline AAL Silva' \\ Thamara Piazza' \\ Tomás M Lacerda' \\ Fernando AC Spencer \\ Netto 2,3 \\ Amaury Cesar Jorge ${ }^{4}$ \\ Péricles AD Duarte ${ }^{4}$ \\ 'College of Medicine, Western Parana \\ State University, Cascavel, PR, Brazil; \\ ${ }^{2}$ Department of Surgery, Western \\ Parana State University Hospital, \\ Cascavel, PR, Brazil; ${ }^{3}$ Department of \\ Emergency Medicine, Western Parana \\ State University Hospital, Cascavel, \\ PR, Brazil; ${ }^{4}$ General ICU, Western \\ Parana State University Hospital, \\ Cascavel, PR, Brazil
}

Correspondence: Péricles AD Duarte General ICU, Hospital Universitário do Oeste do Paraná, Av Tancredo Neves, 3224- Santa Cruz, Cascavel, PR, 85806-470, Brazil

Tel +55 4599972 I298

Email pericles.duarte@uol.com.br
Background: Trauma is a major cause of hospital admissions and is associated with manifold complications and high mortality rates. However, data on intensive care unit (ICU) admissions are scarce in developing and low-income countries, where its incidence has been increasing.

Objectives: To analyze epidemiological and clinical factors and outcomes in adult trauma patients admitted to the ICU of a public teaching hospital in a developing country as well as to identify risk factors for complications in the ICU.

Patients and methods: Retrospective cohort of adult trauma patients admitted to the general ICU of a public teaching hospital in southern Brazil in the year 2012. Demographic, clinical, and outcome data from the ICU were analyzed.

Results: During the study period, 144 trauma patients were admitted ( $83 \%$ male, Acute Physiology and Chronic Health Evaluation Score II =18.6 \pm 7.2, age =33.3 years, 93\% required mechanical ventilation). Of these, $60.4 \%$ suffered a traffic accident (52\% motorcycle), and $31.2 \%$ were victims of violence (aggressions, gunshot wounds, or stabbing); $71 \%$ had brain trauma, $37 \%$ had chest trauma, and $21 \%$ had abdominal trauma. Patients with trauma presented a high incidence of complications, such as infections, acute renal failure, acute respiratory distress syndrome, and thrombocytopenia. The ICU mortality rate was $22.9 \%$.

Conclusion: In a Brazilian public teaching ICU, there was a great variability of trauma etiologies (mainly traffic accidents with motorcycles and victims of violence); patients with trauma had a high incidence of complications and mortality in the ICU.

Keywords: trauma, intensive care, epidemiology, mortality

\section{Introduction}

Trauma represents a serious public health problem and is among the most common causes of mortality and disability, with a significant human, economic, and social cost. ${ }^{1}$ External causes account for higher mortality rates in the young male population living in low-income countries. ${ }^{2}$ The large volume of hospitalized patients due to trauma, with a high morbidity and mortality rate, and a high cost for treatment and rehabilitation of these patients ${ }^{3}$ makes epidemiological studies of great importance for understanding and evaluation of the traumatized patient.

The World Health Organization (WHO) estimates that annual expenditures worldwide due to external causes exceed $\$ 500$ billion. ${ }^{4}$ In Brazil, the total costs of medical treatment of trauma patients are about R $\$ 28-30$ billion (about US\$8-10 billion) per year. ${ }^{5,6}$ Trauma is responsible for $10 \%$ of world mortality ${ }^{7}$ and has an economic repercussion because, in addition to the irreversible loss of a productive member of society, 
many are debilitated, prevented from working, and require rehabilitation. Traumatic brain injury in Brazil generates 125,000 admissions per year and costs annually about US $\$ 70,960,000$; hospital mortality due to this type of trauma is $5.1 / 100,000$ inhabitants per year. $^{8}$

Traffic accidents are a leading trauma mortality etiology in the world, causing 1.25 million deaths per year. ${ }^{9}$ Brazil, in turn, is the fifth highest country in the world regarding the number of deaths in traffic. ${ }^{9}$ On the other hand, our country is experiencing an epidemic of urban violence: Brazil had, in 2000, 34,132 hospital admissions due to aggressions registered in the Sistema Único de Saúde (Brazilian Health System). ${ }^{10}$

\section{Objectives}

To study the epidemiology, complications, and outcomes of adult trauma patients from different mechanisms attended at an intensive care unit (ICU) of a public teaching hospital in Southern Brazil as well as to identify risk factors for complications in the ICU.

\section{Patients and methods Study design and setting}

This was a cohort study, in which the data were obtained retrospectively from the medical records of patients admitted to the adult general 14-beds ICU of the Hospital Universitário do Oeste do Paraná (HUOP) (a public teaching hospital with 198 beds, which serves a region of 27 municipalities with $\sim 1.5$ million inhabitants), in Cascavel (Southern Brazil), during the year 2012, who were admitted for trauma. The HUOP is a general hospital, although it is a reference to trauma care for the region above described.

\section{Patients}

Inclusion criteria were adult patients admitted in the ICU during the study period for trauma (traffic accidents, falls, and violence, among others). The exclusion criteria were: patients admitted to the ICU without diagnosis of trauma or under 18 years old.

\section{Definitions and variables}

- Acute renal failure (ARF): Any serum creatinine level $>50 \%$ of baseline; when it was not known, the value expected by age, gender, and weight; ${ }^{11}$

- Thrombocytopenia: Any platelet count $<100,000$ cells/ $\mathrm{mm}^{3}$;

- Sepsis: According to the criteria by Bone et al, ${ }^{12}$ current at the time of collection;
- Vasoactive drug (VAD) use: Any dose of noradrenaline, dopamine, or vasopressin;

- Previous diseases and comorbidities (eg, COPD, congestive heart failure, chronic renal failure): clinically defined by the healthcare team;

- Infectious complications (such as pneumonia and urinary tract infection): clinical criteria determined by the healthcare team;

- Acute respiratory distress syndrome (ARDS): According to the Berlin criteria. ${ }^{13}$

- Trauma: Any type of injury caused by an external aggressor, including the following: 1) traffic accidents (including rural accidents); 2) falls (of own height or high height, including occupational); 3) violence (gunshot wounds, stabbing, or beatings); and 4) other (including workrelated injuries, such as device related, but excluding falls). The following were not included: severe extensive burn, drowning, and exogenous intoxications (unless secondary to trauma of the above mechanisms).

\section{Statistical methods}

The data were tabulated in a specific worksheet. Descriptive statistical analysis was performed, and percentages expressed as frequency, mean, and SD. The analysis of baseline and epidemiological data and outcome were conducted using the Student's $t$-test, analysis of variance, and Tukey's test, applying a significance of $P<0.05$.

\section{Ethical concerns}

The study was conducted in accordance with the recommendations in Resolution 466/2012 of the Brazilian National Council of Health. This study was approved by the Research Ethics Committee of the Universidade Estadual do Oeste do Paraná, UNIOESTE. According to the study characteristics (retrospective epidemiology study by analyzing data bank and medical records), patient informed consent was waived (but the confidentiality of patient data was guaranteed).

\section{Results}

During the study period (January to December 2012), 441 patients were admitted to the ICU, 144 (32.6\%) with trauma, which were included in the study. The mean admission Acute Physiology and Chronic Health Evaluation Score (APACHE) II of patients with trauma was $18.6 \pm 7.19$, the mean age was $33.3 \pm 14.54$ years, and the ICU mortality was $22.9 \%$ (compared with APACHE II 21.6, 53.4 years, and mortality $28.0 \%$ of nontrauma patients in the same period). 
Among the patients with trauma, the most common were from traffic accidents $(60.4 \%)$ and from violence $(31.2 \%)$. Most of the patients had no previous disease (of patients who had comorbidities, most had falls from their own height). Only $6.9 \%$ of the patients did not undergo invasive mechanical ventilation (MV) (about one third required more than 10 days of MV), whereas $66 \%$ needed VADs. Mortality was similar among patients with trauma due to traffic and violence and higher among patients with falls. Demographic, clinical, and outcome data are presented in Table 1.

Among patients with trauma related to violence, there was a great difference between the most affected sites: while in cases of firearm injury and stabbing, there was a higher incidence of chest and abdominal injuries, in patients/victims of beatings/aggressions, there was a high incidence of isolated brain trauma (Figure 1).

Regarding infectious complications, 66 patients (44.89\%) had pneumonia, $9(6.25 \%)$ had bloodstream or catheter infection, and $3(2 \%)$ had bacterial meningitis.

Of all the patients, $87(60.4 \%)$ had some type of brain trauma injury (BTI), and, of these, $71.3 \%$ were in the traffic trauma group. Among patients with BTI, the mean Glasgow Coma Score (GCS) at hospital admission was $8.8( \pm 5.0)$; head computer tomography revealed $90.8 \%$ had cerebral edema, $65.5 \%$ had subaracnoid hemorrhage, and $28.7 \%$ had hemorrhagic contusion; $22.3 \%$ of the patients with BTI had intracranial pressure (ICP) monitoring; of these, $66.7 \%$ had intracranial hypertension (ICP $>20$ ), and the mean peak ICP was $30.1 \pm 17.31 \mathrm{cmH}_{2} \mathrm{O}$.

Among patients with traffic trauma, the main factor related to hospital mortality was age. In addition, the incidence of complications (such as ARF, ARDS, and thrombocytopenia) was correlated with a higher risk of death. Among the victims of violence, APACHE II score at admission was the main predictor of mortality; also the presence of complications (mainly ARF) correlated with hospital death (Table 2).

According to the data found, a multiparametric analysis was performed, seeking to find independent factors associated with a worse outcome, in patients with trauma due to violence or traffic (Table 3). It was found, through logistic regression, that the independent predictors of worse outcome were, in traffic trauma, the presence of complications (ARDS and ARF). In trauma due to violence, the main variables were initial APACHE and blood transfusions (total number of transfused packed red blood cells), but no variables were found to be independent predictors of mortality (Table 3).

\section{Discussion}

In Brazil (as well as in other underdeveloped and lowincome countries), the proportion of hospitalizations due to external causes has increased steadily in recent years, unlike the developed countries, where there is a tendency for their incidence to fall., ${ }^{4,6,14}$ In our study, the most common etiology of trauma was traffic accident (60.4\% of patients), followed by violence $(31.2 \%)$. This clearly reflects the epidemiological context of the trauma in this country, one of the world leaders in traffic accident trauma and with high rates of violence mortality (close to those in countries in wars). The age range and epidemiological pattern clearly differentiates among the mechanisms of trauma. In traffic trauma and due to violence, young men predominate, similar to the literature.$^{14,15}$ On the other hand, trauma due to falls of own height typically affects older individuals; in the present study, the median age was 55 years, and $20 \%$ were older than 70 years. In high-income countries, there has been a progressive increase in the number of trauma due to falls in the geriatric population in recent years. In Brazil, which is experiencing an upgrowth in the average age and increase in the number of elderly people, it is expected that this incidence will increase in the coming years.

Among the patients with trauma due to violence, the most common cause of ICU admission was due to gunshot and then stabbing. However, mortality did not differ between these two groups. On the other hand, the number of aggression victims, often homeless people with great social problems, is striking.

In addition to varying the etiology of trauma, the age group also interferes with the prognosis of patients. ${ }^{16}$ In the current study, similarly, there was a strong impact of age on mortality: among patients over 55 years of age, mortality was $38.9 \%$, compared with those younger than 55 years $(20.1 \%)$. In this way, age was a predictive factor of mortality, particularly in the traffic accident group (Table 2).

Most patients had high severity trauma: mean Injury Severity Score was 34.6, being higher in patients with trauma due to traffic accidents and violence. The mean APACHE II index at ICU admission was very high (18.6), and this value was even higher in patients who died, particularly in patients who were victims of violence. Despite the considerations about the efficiency of APACHE II in patients with trauma, the predictive power of this score is comparable to specific trauma scores in ICU trauma patients. ${ }^{17}$

The impact of smoking and alcoholism on the morbidity and mortality of trauma is controversial. ${ }^{18}$ In the current study, $11.1 \%$ were smokers and $14.6 \%$ alcohol users. On the other hand, the consumption of illicit drugs (mainly marijuana and crack cocaine) was more common among victims 
Table I Demographic, clinical, and outcome data

\begin{tabular}{|c|c|c|c|c|c|}
\hline Variables & Total & Traffic & Violence & Falls & Others \\
\hline$n$ & 144 & 87 & 45 & 10 & 2 \\
\hline Age, mean $\pm S D$ & $33.3 \pm 14.5$ & $31.4 \pm 13.6$ & $30.9 \pm 11.1$ & $53.7 \pm 19.2$ & $4 I .5 \pm 7.8$ \\
\hline$<45$ & $80.6 \%$ & $81.6 \%$ & $91.1 \%$ & $30 \%$ & $50 \%$ \\
\hline $45-70$ & $17.4 \%$ & $17.2 \%$ & $8.9 \%$ & $50 \%$ & $50 \%$ \\
\hline$>70$ & $2.0 \%$ & $1.1 \%$ & 0 & $20 \%$ & 0 \\
\hline Male gender, \% & $82.6 \%$ & $78.2 \%$ & $91.1 \%$ & $80 \%$ & $100 \%$ \\
\hline Admission APACHE II, mean \pm SD & $18.6 \pm 7.2$ & $19.5 \pm 6.9$ & $17.0 \pm 7.9$ & $20.1 \pm 6.1$ & $16 \pm 5.6$ \\
\hline ISS, mean \pm SD & $34.6 \pm 13.9$ & $36.2 \pm 15.1$ & $33.3 \pm 11.6$ & $29.0 \pm 11.8$ & $20.5 \pm 6.4$ \\
\hline $\mathrm{BMI}$, mean $\pm \mathrm{SD}$ & $26.2 \pm 4.9$ & $27.0 \pm 4.8$ & $26.0 \pm 4.9$ & $24.0 \pm 3.9$ & $26.1 \pm 26.1$ \\
\hline Smoking, \% & $10.4 \%$ & $10.3 \%$ & $13.3 \%$ & 0 & 0 \\
\hline Alcoholism, \% & $14.6 \%$ & $6.9 \%$ & $24.4 \%$ & $30 \%$ & $50 \%$ \\
\hline Illicit drugs use, $\%$ & $6.9 \%$ & $3.4 \%$ & $14.9 \%$ & 0 & 0 \\
\hline \multicolumn{6}{|l|}{ Comorbidities, \% } \\
\hline COPD & $1.4 \%$ & $2.3 \%$ & 0 & 0 & 0 \\
\hline $\mathrm{SH}$ & $10.4 \%$ & $10.3 \%$ & $4.2 \%$ & $30 \%$ & $50 \%$ \\
\hline Others & $16.7 \%$ & $16.1 \%$ & $14.9 \%$ & $20 \%$ & $50 \%$ \\
\hline \multicolumn{6}{|l|}{ Complications and outcomes } \\
\hline \multicolumn{6}{|l|}{ Complications, \% } \\
\hline ARDS & $52.1 \%$ & $56.3 \%$ & $46.7 \%$ & $40 \%$ & $50 \%$ \\
\hline ARF & $22.2 \%$ & $16.1 \%$ & $26.7 \%$ & $50 \%$ & $50 \%$ \\
\hline Dialysis need & $11.1 \%$ & $9.2 \%$ & $11.1 \%$ & $30 \%$ & 0 \\
\hline Infections (ICU-acquired) & $77.8 \%$ & $77.0 \%$ & $80.8 \%$ & $60 \%$ & $50 \%$ \\
\hline Invasive MV length of time, days, mean $\pm S D$ & $9.8 \pm 13.4$ & $11.5 \pm 16.0$ & $7.8 \pm 8.2$ & $8.5 \pm 4.9$ & $7.5 \pm 2.5$ \\
\hline 0 & $6.9 \%$ & $4.6 \%$ & $13.3 \%$ & 0 & 0 \\
\hline $1-2$ & $14.6 \%$ & $11.5 \%$ & $24.4 \%$ & 0 & 0 \\
\hline $3-5$ & $23.6 \%$ & $21.8 \%$ & $24.4 \%$ & $30 \%$ & $50 \%$ \\
\hline $6-9$ & $18.8 \%$ & $21.8 \%$ & $11.1 \%$ & $30 \%$ & 0 \\
\hline $10-14$ & $22.2 \%$ & $23.0 \%$ & $15.6 \%$ & $40 \%$ & $50 \%$ \\
\hline$>14$ & $13.9 \%$ & $17.3 \%$ & $11.2 \%$ & 0 & 0 \\
\hline Lowest $\mathrm{PaO}_{2} / \mathrm{FiO}_{2}$, mean $\pm \mathrm{SD}$ & $198.6 \pm 108.2$ & $184.3 \pm 105.4$ & $182.6 \pm 105.3$ & $218.7 \pm 92.9$ & $182.4 \pm 143.7$ \\
\hline$<100$ & $19.5 \%$ & $23.0 \%$ & $15.5 \%$ & $10 \%$ & $50 \%$ \\
\hline $100-199$ & $42.1 \%$ & $39.1 \%$ & $51.1 \%$ & $40 \%$ & 0 \\
\hline $200-299$ & $24.8 \%$ & $24.1 \%$ & $22.2 \%$ & $30 \%$ & $50 \%$ \\
\hline$>299$ & $13.5 \%$ & $13.8 \%$ & $11.1 \%$ & $20 \%$ & 0 \\
\hline Highest PEEP, $\mathrm{cmH}_{2} \mathrm{O}$, mean \pm SD & $7.7 \pm 3.9$ & $8.3 \pm 4.4$ & $6.9 \pm 2.4$ & $7.2 \pm 4.6$ & $7.0 \pm 1.4$ \\
\hline$<6$ & $33.3 \%$ & $27.6 \%$ & $44.4 \%$ & $50 \%$ & 0 \\
\hline $6-10$ & $52.8 \%$ & $56.3 \%$ & $46.7 \%$ & $40 \%$ & $100 \%$ \\
\hline $11-15$ & $9.0 \%$ & $10.3 \%$ & $8.9 \%$ & 0 & 0 \\
\hline$>15$ & $4.9 \%$ & $5.8 \%$ & 0 & $10 \%$ & 0 \\
\hline Lowest prehospital GCS, mean \pm SD & $8.9 \pm 4.7$ & $7.8 \pm 4.2$ & $10.5 \pm 5.0$ & $10.0 \pm 5.1$ & 7.5 \\
\hline $3-8$ & $48.6 \%$ & $59.8 \%$ & $28.9 \%$ & $40 \%$ & $50 \%$ \\
\hline $9-13$ & $26.4 \%$ & $27.6 \%$ & $24.4 \%$ & $20 \%$ & $50 \%$ \\
\hline$>13$ & $25.0 \%$ & $12.6 \%$ & $46.7 \%$ & $40 \%$ & 0 \\
\hline ICP catheter use, \% & $14.6 \%$ & $16.19 \%$ & $6.7 \%$ & $30 \%$ & 0 \\
\hline VAD need, $\%$ & $66.0 \%$ & $67.8 \%$ & $60.0 \%$ & $70.0 \%$ & $100 \%$ \\
\hline ICU length of time, days, mean \pm SD & $12.9 \pm 14.3$ & $\mid 4.8 \pm 17.0$ & $9.8 \pm 8.3$ & $7.3 \pm 5.6$ & $7.0 \pm 2.8$ \\
\hline Hospital length of time, days, mean $\pm S D$ & $22.9 \pm 15.4$ & $25.9 \pm 22.6$ & $18.8 \pm 12.9$ & $13.5 \pm 16.0$ & $11.5 \pm 3.5$ \\
\hline ICU mortality, \% & $22.9 \%$ & $20.7 \%$ & $20 \%$ & $50 \%$ & $50 \%$ \\
\hline Hospital mortality, \% & $24.3 \%$ & $23.0 \%$ & $20 \%$ & $50 \%$ & $50 \%$ \\
\hline
\end{tabular}

Abbreviations: APACHE, Acute Physiology and Chronic Health Evaluation; ISS, Injury Severity Score; BMI, body mass index; SH, systemic hypertension; ARDS, acute respiratory distress syndrome; $\mathrm{ARF}$, acute renal failure; $\mathrm{MV}$, mechanical ventilation; $\mathrm{PaO}_{2}$, arterial pressure of oxygen; $\mathrm{FiO}_{2}$, fraction of inspired oxygen; $\mathrm{PEEP}$, positive endexpiratory pressure; ICP, intracranial pressure; VAD, vasoactive drugs; ICU, intensive care unit; GCS, Glasgow Coma Score. 
100

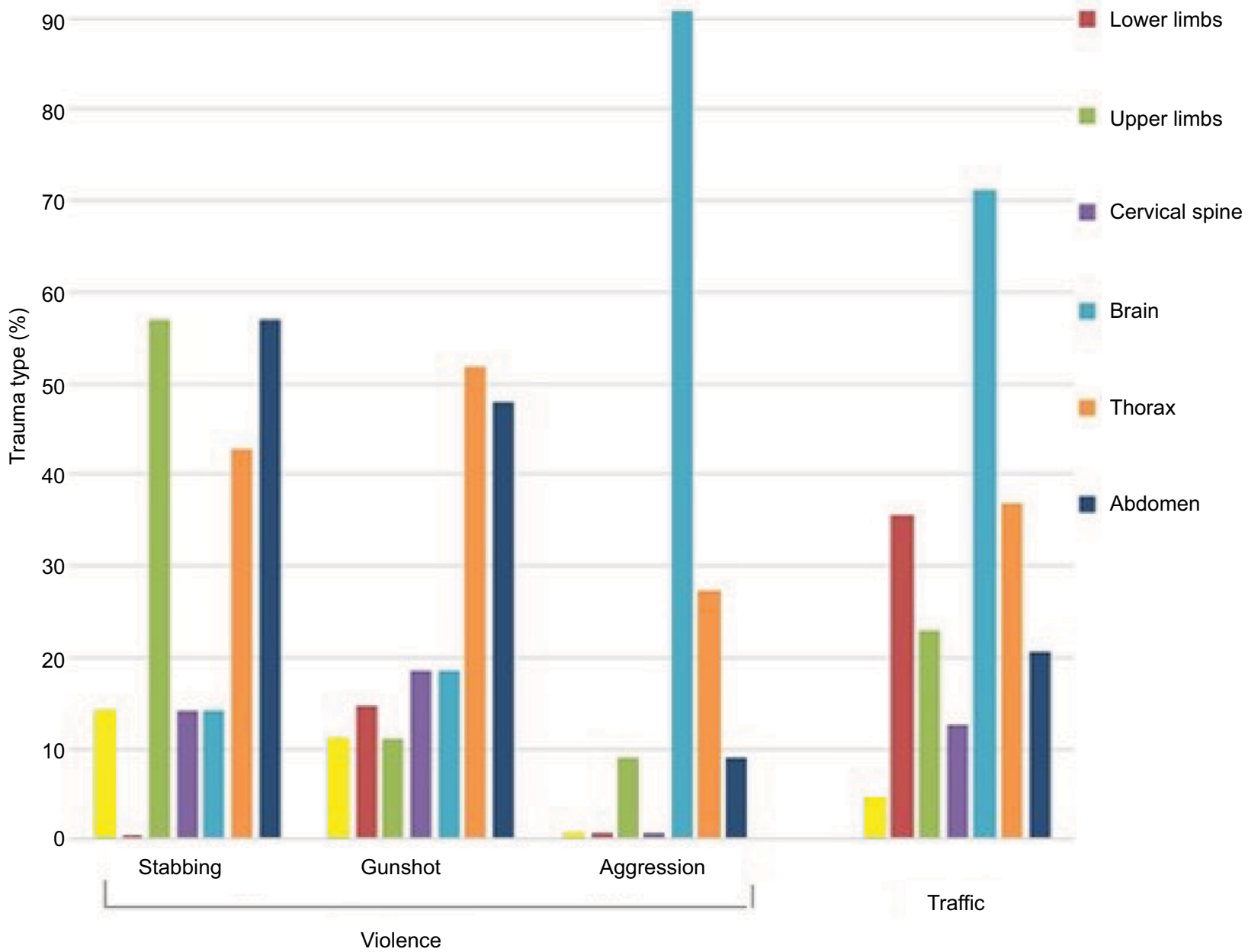

Figure I Trauma by violence ( $n=45)$ or traffic accidents ( $n=87$ ): region (site) of the body affected, according to the type of trauma. The total percent of each type of trauma can be higher than $100 \%$.

of violence. However, none of these habits were related to higher mortality.

The most frequent comorbidities found in our study were systemic hypertension and diabetes mellitus (DM). Most of the patients had no previous major illnesses, except for patients with falls, of whom $50 \%$ had some type of chronic disease before the trauma. A negative impact of the presence of comorbidities on survival after trauma has been previously found. ${ }^{16}$ In our study, $32 \%$ of patients who had some comorbidity died, which did not differ significantly from patients without comorbidities. Possibly this lack of influence of age in the current study was due to the low incidence of falls in the group (and, therefore, of the elderly with comorbidities).

On the other hand, the incidence of complications during the ICU was high. In our study, ARDS was the most frequent complication, with an incidence of $52.1 \%$, being common in all types of trauma. Factors such as chest trauma (most common in victims of traffic accidents or violence), infections, sepsis, BTI, bronchoaspiration, or alcoholism (predisposing to TRALI [transfusion-related acute lung injury]) may have interfered with this high incidence of ARDS in our population. ${ }^{19,20}$ Only $4 \%$ of the patients needed prone position, $29.33 \%$ required neuromuscular block (pancuronium or atracurium by intermittent application), and the hospital mortality was $34.7 \%$, values similar to those previously found. ${ }^{22}$ The incidence of ARF was $22.2 \%$, being higher in patients with falls. Possibly this was due to the higher age and more comorbidities (such as hypertension and DM) in this population, as well as an increased risk of nephrotoxicity. ${ }^{23}$ The presence of ARF had an important clinical impact: 11.11\% 
Table 2 Differences between deaths and survivors among patients with trauma by traffic accidents $(n=87)$ and violence $(n=45)$

\begin{tabular}{|c|c|c|c|c|}
\hline Variables & Total & Alive (Hospital) & Death (Hospital) & $P$-value \\
\hline Traffic & $n=87$ & $n=67$ & $n=20$ & \\
\hline \multicolumn{5}{|l|}{ Place of accident, $\%$} \\
\hline Town & $67.8 \%$ & $70.1 \%$ & $60 \%$ & 0.563 \\
\hline Road (including countryside) & $29.9 \%$ & $26.9 \%$ & $40 \%$ & 0.396 \\
\hline Countryside (excluding road) & $2.3 \%$ & $3.0 \%$ & 0 & 0.944 \\
\hline \multicolumn{5}{|l|}{ Patient's vehicle, \% } \\
\hline By foot (no vehicle) & $9.2 \%$ & $8.9 \%$ & $10 \%$ & 0.765 \\
\hline Bike & $5.7 \%$ & $4.5 \%$ & $10 \%$ & 0.700 \\
\hline Motorcycle & $52.9 \%$ & $55.2 \%$ & $45 \%$ & 0.583 \\
\hline Car & $31.0 \%$ & $30.0 \%$ & $35 \%$ & 0.872 \\
\hline Truck & $1.1 \%$ & $1.5 \%$ & 0 & 0.518 \\
\hline \multicolumn{5}{|l|}{ Organs affected by trauma, $\%$} \\
\hline Brain & $71.3 \%$ & $71.6 \%$ & $70 \%$ & 0.889 \\
\hline Cervical spine & $12.6 \%$ & $13.4 \%$ & $10 \%$ & 0.983 \\
\hline Thorax & $36.8 \%$ & $41.8 \%$ & $20 \%$ & 0.131 \\
\hline Abdomen & $20.7 \%$ & $20.9 \%$ & $20 \%$ & 0.819 \\
\hline Pelvis & $4.6 \%$ & $3.0 \%$ & $10 \%$ & 0.479 \\
\hline APACHE II, mean \pm SD & $19.5 \pm 6.9$ & $18.9 \pm 6.9$ & $21.6 \pm 6.5$ & 0.126 \\
\hline ISS, mean \pm SD & $36.2 \pm 15.1$ & $36.0 \pm 15.5$ & $36.9 \pm 13.9$ & 0.817 \\
\hline Male gender, \% & $78.2 \%$ & $77.6 \%$ & $80 \%$ & 0.935 \\
\hline Age, years, mean \pm SD & $31.4 \pm 13.6$ & $29.7 \pm 12.8$ & $37.1 \pm 15.2$ & 0.032 \\
\hline Lowest GCS, mean \pm SD & $7.5 \pm 4.5$ & $7.2 \pm 4.5$ & $8.6 \pm 4.5$ & 0.229 \\
\hline ARDS, \% & $56.3 \%$ & $49.2 \%$ & $80 \%$ & 0.030 \\
\hline VAD need (any type), \% & $67.8 \%$ & $64.2 \%$ & $80 \%$ & 0.290 \\
\hline Thrombocytopenia, \% & $40.2 \%$ & $34.3 \%$ & $60 \%$ & 0.073 \\
\hline ARF, \% & $16.1 \%$ & $8.9 \%$ & $40 \%$ & 0.003 \\
\hline Dialysis, \% & $9.2 \%$ & $4.5 \%$ & $25 \%$ & 0.019 \\
\hline ICU length of time (days), mean \pm SD & $14.8 \pm 17.0$ & $13.3 \pm 8.3$ & $19.7 \pm 32.2$ & 0.141 \\
\hline Hospital length of time (days), mean $\pm S D$ & $25.9 \pm 22.6$ & $27.0 \pm 19.2$ & $22.1 \pm 31.8$ & 0.399 \\
\hline Violence & $n=45$ & $n=36$ & $n=9$ & \\
\hline \multicolumn{5}{|l|}{ Type of trauma, \% } \\
\hline Gunshot & $60 \%$ & $52.8 \%$ & $88.9 \%$ & 0.110 \\
\hline Stabbing & $15.6 \%$ & $16.7 \%$ & $11.1 \%$ & 0.918 \\
\hline Aggression & $24.4 \%$ & $30.5 \%$ & 0 & 0.140 \\
\hline \multicolumn{5}{|l|}{ Organs affected by trauma, $\%$} \\
\hline Brain & $35.6 \%$ & $41.7 \%$ & $11.1 \%$ & 0.186 \\
\hline Cervical spine & $13.3 \%$ & $13.9 \%$ & $11.1 \%$ & 0.742 \\
\hline Thorax & $44.4 \%$ & $41.7 \%$ & $55.5 \%$ & 0.708 \\
\hline Abdomen & $40 \%$ & $30.5 \%$ & $77.7 \%$ & 0.028 \\
\hline Pelvis & $8.9 \%$ & $11.1 \%$ & 0 & 0.694 \\
\hline Upper limbs & $17.8 \%$ & $22.2 \%$ & 0 & 0.284 \\
\hline Lower limbs & $8.9 \%$ & $4.4 \%$ & $22.2 \%$ & 0.284 \\
\hline APACHE II, mean \pm SD & $17.0 \pm 7.9$ & $15.3 \pm 7.2$ & $24.1 \pm 6.8$ & 0.002 \\
\hline ISS, mean \pm SD & $33.3 \pm 11.6$ & $32.9 \pm 12.2$ & $34.8 \pm 9.1$ & 0.665 \\
\hline Male gender, \% & $91.1 \%$ & $91.7 \%$ & $88.9 \%$ & 0.695 \\
\hline Age, years, mean $\pm S D$ & $30.9 \pm 11.1$ & $30.9 \pm 12.2$ & $31.1 \pm 5.0$ & 0.962 \\
\hline Lowest GCS, mean \pm SD & $10.4 \pm 4.8$ & $10.5 \pm 4.7$ & $9.8 \pm 5.6$ & 0.703 \\
\hline ARDS, \% & $46.7 \%$ & $41.7 \%$ & $66.7 \%$ & 0.331 \\
\hline VAD need (any type), \% & $60 \%$ & $55.6 \%$ & $77.8 \%$ & 0.403 \\
\hline Thrombocytopenia, \% & $19.1 \%$ & $13.1 \%$ & $44.4 \%$ & 0.099 \\
\hline ARF, \% & $25.5 \%$ & $15.8 \%$ & $66.7 \%$ & 0.007 \\
\hline Dialysis, \% & $10.6 \%$ & $5.3 \%$ & $33.3 \%$ & 0.069 \\
\hline ICU length of time (days), mean \pm SD & $9.8 \pm 8.3$ & $9.9 \pm 8.0$ & $10.3 \pm 9.6$ & 0.898 \\
\hline Hospital length of time (days), mean $\pm S D$ & $18.8 \pm 13.0$ & $19.9 \pm 12.9$ & $13.9 \pm 13.3$ & 0.220 \\
\hline
\end{tabular}

Abbreviations: APACHE, Acute Physiology and Chronic Health Evaluation; ISS, Injury Severity Score; GCS, Glasgow Coma Score; ARDS, acute respiratory distress syndrome; ARF, acute renal failure; MV, mechanical ventilation; VAD, vasoactive drugs; ICU, intensive care unit. 
Table 3 Parameters obtained through the application of logistic regression to find the factors associated with the death of patients with trauma from traffic accidents $(n=87)$

\begin{tabular}{llll}
\hline Variable & Value & $P$-value & OR [IC95\%] \\
\hline Intercept & -3.062 & 0.000 & \\
ARDS & 1.442 & 0.040 & $4.230[1.071-16.7 I I]$ \\
ARF & 1.590 & 0.049 & $4.904[1.009-23.838]$ \\
\hline
\end{tabular}

Note: In patients with trauma by violence, no independent predictive factors were found.

Abbreviations: IC $95 \%$, lower limit of interval with $95 \%$ confidence; ARDS, acute respiratory distress syndrome; ARF, acute renal failure.

required dialysis, and hospital mortality was $61.29 \%$. A higher incidence of complications among male patients with trauma has been found. ${ }^{21}$ This was also found in our study: $84 \%$ of patients who had ARDS or ARF were men. There was a high incidence of infectious complications, particularly pneumonia (44\%). This result clearly demonstrates the need for infectious prevention and surveillance in this population.

Almost two thirds of the patients presented BTI, being more common in patients with trauma from traffic accidents. Despite the fact that most patients had moderate or severe BTI, the use of intracranial pressure monitoring was low. Despite the controversies regarding the use of ICP monitoring among patients with BTI, ${ }^{24}$ the authors recognize that this monitoring modality was probably used in a suboptimal amount, which emphasizes the need for more studies and improving of trauma data in developing and low-income countries. The presence of BTI increases morbidity and mortality in trauma, ${ }^{25}$ particularly by high incidence of respiratory complications. ${ }^{20}$ In the current study, half $(52.9 \%)$ of the patients with BTI had ARDS during ICU admission, with a high mortality rate.

In our study, most patients $(75 \%)$ had a $\mathrm{GCS}<13$ at the trauma site, and almost half $(48.2 \%)$ had $<8$. As previously found, ${ }^{26}$ patients with severe neurologic injury (GCS $\left.\leq 8\right)$ had similar age, gender, and comorbidities at hospital admission compared to those with less severe neurological injury (GCS $>8$ ) However, these patients had a higher incidence of complications, such as ARDS and ARF, and higher ICU and hospital mortality rates.

The main factors related to mortality among patients with trauma from traffic accident were the organ of the body affected by the trauma, age, and the presence of complications, such as ARDS, thrombocytopenia, ARF, and the need for dialysis. Among patients with trauma due to violence, the presence of complications was also associated with higher mortality, as well as APACHE II admission. The development of complications, whether cardiovascular, respiratory, renal, urinary, or gastrointestinal, has been found to be related to an increase in mortality in patients who are victims of trauma, particularly from traffic. ${ }^{27}$

The current study has some limitations, some of which are inherent to its methodology and design. It is a single center study, which reduces the number evaluated. Because it was an observational study, the impact of strategies aimed at reducing morbidity and mortality in these patients, such as neurological monitoring, infection prevention bundles, or ventilatory strategies, was not evaluated. However, the objective of the study was to evaluate the "real life" situation of patients with trauma in an ICU in a Brazilian university hospital, and, therefore, the design of the study was set up for this purpose.

\section{Implications of the study}

The data clearly demonstrate a dissociation between strategies and the literature from developed countries (such as multimodal neurological monitoring) and the complex situation of high incidence of trauma with great social impact of the reality of a developing low-income country. We hope that these data may help researchers and health workers in low middle-income countries to better help and manage trauma patients in the ICU environment.

\section{Conclusion}

In a Brazilian public teaching ICU, there was a great variability of trauma etiologies (mainly traffic accidents with motorcycles and victims of violence); patients with trauma had a high incidence of complications and mortality in the ICU.

\section{Author contributions}

GFP, TAALS, TP, and TML collected the data, analyzed the data, and wrote the manuscript; FACSN, ACJ, and PADD designed the study, analyzed the data, wrote the manuscript, and reviewed the manuscript. All the authors read and approved the final manuscript. All authors contributed toward data analysis, drafting and revising the paper, gave final approval of the version to be published, and agree to be accountable for all aspects of the work

\section{Disclosure}

The authors report no conflicts of interest in this work.

\section{References}

1. Alberdi F, García I, Atutxa L, et al. Epidemiología del trauma grave. Med Intensiva. 2014;38(9):580-588.

2. Mathers C, Fat DM, Boerma JT. The Global Burden of Disease: 2004 Update. Geneva: World Health Organization; 2008.

3. DiMaggio C, Ayoung-Chee P, Shinseki M, et al. Traumatic injury in the United States: in-patient epidemiology 2000-2011. Injury. 2016;47(7):1393-1403. 
4. GBD 2015 Disease and Injury Incidence and Prevalence Collaborators. Global, regional, and national incidence, prevalence, and years lived with disability for 310 diseases and injuries, 1990-2015: a systematic analysis for the Global Burden of Disease Study 2015. Lancet. 2016;388(10053):1545-1602.

5. Plano Nacional de Saúde: PNS 2016-2019. Brasil: Ministério da Saúde. Brasília; s.n; 2016. 91 p. Portuguese.

6. IPEA. Acidentes de trânsito nas rodovias federais brasileiras caracterização, tendências e custos para a sociedade. IPEA. 2015:7-34. Portuguese

7. Lozano R, Naghavi M, Foreman K, et al. Global and regional mortality from 235 causes of death for 20 age groups in 1990 and 2010: a systematic analysis for the Global Burden of Disease Study 2010. Lancet. 2012; 380(9859):2095-2128.

8. de Almeida CE, de Souza Filho JL, Dourado JC, Gontijo PA, Dellaretti MA, Costa BS. Traumatic brain injury epidemiology in Brazil. World Neurosurg. 2016;87:540-547.

9. World Health Organization. Global Status Report on Road Safety 2015. Geneva: WHO Press; 2015.

10. Souza ER. Masculinidade e violência no Brasil: contribuições para a reflexão no campo da saúde. Ciência \& Saúde Coletiva. 2005;10(1): 59-70. Portuguese.

11. Mehta RL, Kellum JA, Shah SV, et al. Acute Kidney Injury Network: report of an initiative to improve outcomes in acute kidney injury. Crit Care. 2007;11:R31.

12. Bone RC, Sibbald WJ, Sprung CL. The ACCP-SCCM consensus conference on sepsis and organ failure. Chest. 1992;101(6):1481-1483.

13. ARDS Definition Task Force. Acute respiratory distress syndrome: the Berlin definition. JAMA. 2012;307(23):2526-2533.

14. Sise RG, Calvo RY, Spain DV, Weiser TG, Staudenmayer KL. The epidemiology of trauma-related mortality in the United States from 2002 to 2010. J Trauma Acute Care Surg. 2014;76(4):913-919.

15. Wui LW, Shaun GE, Ramalingam G, Wai KM. Epidemiology of trauma in an acute care hospital in Singapore. J Emerg Trauma Shock. 2014;7(3):174-179.

16. Kahl JE, Calvo RY, Sise MJ, Sise CB, Thorndike JF, Shackford SR. The changing nature of death on the trauma service. J Trauma Acute Care Surg. 2013;75(2):195-201.
17. Wong DT, Barrow PM, Gomez M, McGuire GP. A comparison of the Acute Physiology and Chronic Health Evaluation (APACHE) II score and the Trauma-Injury Severity Score (TRISS) for outcome assessment in intensive care unit trauma patients. Crit Care Med. 1996;24(10): 1642-1648.

18. Mehta AJ. Alcoholism and critical illness: a review. World J Crit Care Med. 2016;5(1):27-35.

19. Bakowitz M, Bruns B, McCunn M. Acute lung injury and the acute respiratory distress syndrome in the injured patient. Scand J Trauma Resusc Emerg Med. 2012;20:54.

20. Weirich PP, Tozo TC, Wandeur V, Duarte PAD. Moderate/severe acute respiratory distress syndrome in patients with or without traumatic brain injury. Trauma. 2015;17(4):274-281.

21. Haider AH, Crompton JG, Oyetunji T, et al. Females have fewer complications and lower mortality following trauma than similarly injured males: a risk adjusted analysis of adults in the National Trauma Data Bank. Surgery. 2009;146(2):308-315.

22. Cook A, Norwood S, Berne J. Ventilator-associated pneumonia is more common and of less consequence in trauma patients compared with other critically ill patients. J Trauma. 2010;69(5):1083-1091.

23. Eriksson M, Brattström O, Mårtensson J, Larsson E, Oldner A. Acute kidney injury following severe trauma: risk factors and long-term outcome. J Trauma Acute Care Surg. 2015;79(3):407-412.

24. Lipsky AM, Karsteadt LL, Gausche-Hill M, et al. A comparison of rural versus urban trauma care. J Emerg Trauma Shock. 2014;7(1): $41-46$.

25. Aras Y, Sabanci PA, Unal TC, Aydoseli A, Isgi N. Epidemiologic study in hospitalized patients with head injuries. Eur J Trauma Emerg Surg. 2017;43(4):467-473.

26. Mascia L, SakrY, Pasero D, et al. Extracranial complications in patients with acute brain injury: a post-hoc analysis of the SOAP study. Intensive Care Med. 2008;34(4):720-727.

27. Zwerling C, Peek-Asa C, Whitten PS, Choi SW, Sprince NL, Jones MP. Fatal motor vehicle crashes in rural and urban areas: decomposing rates into contributing factors. Inj Prev. 2005;11(1):24-28.
Open Access Emergency Medicine

\section{Publish your work in this journal}

The Open Access Emergency Medicine is an international, peerreviewed, open access journal publishing original research, reports, editorials, reviews and commentaries on all aspects of emergency medicine. The manuscript management system is completely online and includes a very quick and fair peer-review system, which is all

\section{Dovepress}

easy to use. Visit http://www.dovepress.com/testimonials.php to read real quotes from published authors 